\title{
Modification of inorganic binder used for sand core-making in foundry practice
}

\author{
Fang-hai Xin, *Wei-hua Liu, Lai Song, Ying-min Li
}

Shenyang University of Technology, Shenyang 110870, China

\begin{abstract}
With modified water glass as binder and the introduction of micro silicon powders into the coremaking process, an improvement was made to the tensile strength and collapsibility of the sand core. The potassium hydroxide, sodium hexametaphosphate and white sugar were applied as the modifiers of water glass. The optimum proportion of the modifiers was determined through the combination of single factor test and orthogonal test. The optimum proportion of water glass, potassium hydroxide, sodium hexametaphosphate and white sugar is 1000: 40: 5: 5 (wt.). In terms of weight, modified binder and micro silicon powders accounted for $2 \%$ and $0.6 \%$ of sand, respectively. The sand core was hardened by going through a warm core box process, in which the temperature of core box was $150{ }^{\circ} \mathrm{C}$, and the compressed hot air was blown at $120{ }^{\circ} \mathrm{C}$ for $40 \mathrm{~s}$ under a pressure of $0.2 \mathrm{MPa}$. As for the sand core bonded with modified water glass, the tensile strength is $2.46 \mathrm{MPa}$ at room temperature $\left(\sigma_{0}\right)$ and $2.49 \mathrm{MPa}$ at $25{ }^{\circ} \mathrm{C}$ and $40 \% \mathrm{RH}$ for $24 \mathrm{~h}\left(\sigma_{24}\right)$, which are 2 times more than that with unmodified binder. The bonded strengths of sand core are increased as a result of the reaction between $-\mathrm{OH}$ groups from addition of potassium hydroxide and $\mathrm{SiO}_{2}$ particles widely distributed in the sand core. Comparing with the sand core bonded with unmodified water glass, the high temperature residual tensile strength $\left(\sigma_{\mathrm{r}}\right)$ of sand core bonded with modified water glass under $600{ }^{\circ} \mathrm{C}$ for $5 \mathrm{~min}$, is sharply reduced from $0.20 \mathrm{MPa}$ to $0.01 \mathrm{MPa}$. By the comparison with unmodified water glass, the dynamic viscosity of the modified water glass and the flowability of molding sand using modified water glass are increased from $74 \mathrm{mPa} \cdot \mathrm{s}$ and $2.15 \mathrm{~g}$ to $80 \mathrm{mPa} \cdot \mathrm{s}$ and $2.21 \mathrm{~g}$, respectively. As revealed by FT-IR analysis, new groups including $\mathrm{PO}_{3}{ }^{-}, \mathrm{PO}_{4}{ }^{3-}$, and $\mathrm{Si}-\mathrm{O}-\mathrm{C}$ appear in the molecular structure of modified water glass, which are beneficial to the collapsibility of sand core.
\end{abstract}

Key words: inorganic binder; modified water glass; tensile strength; collapsibility; warm box core-making process CLC numbers: TG221 .1

Document code: A

Article ID: 1672-6421(2020)05-341-06

I Tn the process of casting, it is inevitable that the traditional organic binder will pollute the environment ${ }^{[1]}$. With the increasingly strict requirements of environmental protection, the inorganic binder has attracted more attention ${ }^{[2,3]}$. Water glass binder, a kind of inorganic binder, which is usually used in aluminum alloy casting, has some advantages in environmental protection because of its non-toxic nature and low gas evolution in casting ${ }^{[3,4]}$. However, due to the low bond strength, the amount of unmodified water glass accounts for as much as $6.0 \%-8.0 \%$ of the weight of molding sand ${ }^{[5]}$. At the same time, the molding sand using unmodified water glass has poor collapsibility ${ }^{[6,7]}$. These disadvantages limit the

\section{*Wei-hua Liu}

Male, born in 1968, Associate Professor, Ph.D. His research interest mainly focuses on foundry materials. To date, he has published over 30 technical papers.

E-mail: 974942647@qq.com

Received: 2020-03-26; Accepted: 2020-08-11 application of water glass binder in large scale. In order to improve the performance of water glass binder, many research works have been published in recent years. The two-component binder system, which is the combination of micro silica powder and water glass, was studied ${ }^{[8,9]}$, and the positive effect of micro silica powder on strengths of sand core was found. Sun et al. ${ }^{[10]}$ studied the effect of a surface active agent on properties of sand core bonded with water glass, and sodium dodecyl and polyacrylamide were introduced as modifiers to improve the collapsibility of the sand core. Yang ${ }^{[1]}$ improved the collapsibility of the sand core by adding a certain proportion of ultrafine powder consisting of $\mathrm{Al}_{2} \mathrm{O}_{3}, \mathrm{ZnO}, \mathrm{TiO}_{2}$ and $\mathrm{MgO}$. Zhu et al. ${ }^{[12]}$ studied the modification of polyethylene oxide on water glass, and found that polyethylene oxide had positive effects on both strengths and collapsibility of the sand core. A new silicate-phosphate binder system was introduced by Leonid ${ }^{[13]}$, and the strengths and collapsibility of the sand core using the new binder were both improved. 
Despite the modified effect of water glass by organic and inorganic additives being positive, some modifiers are not readily available and the preparation process is complicated to some extent. In this study, based on the consideration of lowcost and common availability, sodium hexametaphosphate, white sugar and potassium hydroxide were employed to modify water glass to enhance the strength and collapsibility of a sand core. Both the single factor test and orthogonal test were conducted to optimize the additional amounts of different modifiers. At the same time, micro silica powder was added during the process of sand mixing. Depending on the research status, the addition amount of water glass and micro silica powder was determined, which accounted for $2 \%$ and $0.6 \%$ by weight of sand, respectively. The sand core was prepared through the warm box core-making process. Moreover, an investigation was conducted into the tensile strength and collapsibility of the sand core as prepared with the optimal proportion of modifiers. The Fourier-transform infrared spectroscopy (FT-IR) analysis of water glass was performed to reveal the mechanism of collapsibility improvement of the sand core.

\section{Experimental procedure}

\subsection{Materials and equipment}

The Dalin sand "ZGS- 50/100(60)" was used in this study. The modified water glass was prepared under laboratory conditions. Potassium hydroxide, sodium hexametaphosphate, white sugar and micro silica powders were purchased from Liaoning Xinxing Co., Ltd., China. The content of $\mathrm{SiO}_{2}$ in micro silica powders was close to $93 \%$. A cold-box/hot-box/ inorganic process sand core sample making machine (MLWA1, Suzhou Mingzhi Technology Co., Ltd., China) was employed.

\subsection{Experiment method}

The water glass and potassium hydroxide were added together into a three-necked flask, and then the mixture was stirred for $10 \mathrm{~min}$. When the mixture was heated to $60{ }^{\circ} \mathrm{C}$, sodium hexametaphosphate was added, and the stirring was continued for $20 \mathrm{~min}$. Then, when the mixture was cooled to $30^{\circ} \mathrm{C}$, white sugar was added, and the stirring was maintained for another $10 \mathrm{~min}$ to complete the preparation of the inorganic binder. The production process of the sand core was as follows. Firstly, the sand $(1 \mathrm{~kg})$ was mixed with binder $(20 \mathrm{~g})$ and micro silica powder $(6 \mathrm{~g})$ in a sand mixer for $120 \mathrm{~s}$. Then, the sand mixture was used to prepare the standard " 8 " - shape sand core samples by the sand core-making machine. Lastly, the sand core was bonded by a warm core box process in which the temperature of the core box was $150{ }^{\circ} \mathrm{C}$, and compressed hot air of $120^{\circ} \mathrm{C}$ was blown for $40 \mathrm{~s}$ under a pressure of $0.2 \mathrm{MPa}$.

The influences of the selected modifiers on the properties of sand cores with addition of $0.6 \%$ (wt.) micro silica powder were firstly explored by single factor test. Then, in order to further improve the performance of the modified water glass and optimize the addition amount of each modifier, the orthogonal experiment was designed based on the results of the single factor test. To evaluate the effects of modification, the strengths of the sand core with unmodified water glass and $0.6 \mathrm{wt} . \%$ micro silicon powders, prepared under the same conditions, were also measured.

\subsection{Testing method}

The tensile strength of the sand core was measured using the "SWY" type testing machine. The tensile strength at room temperature $\left(\sigma_{0}\right)$ and at $25{ }^{\circ} \mathrm{C}$ and $40 \% \mathrm{RH}$ for $24 \mathrm{~h}\left(\sigma_{24}\right)$, as well as the high temperature residual tensile strength $\left(\sigma_{\mathrm{r}}\right)$ at $600{ }^{\circ} \mathrm{C}$ (the approximate temperature of molding sand after aluminum alloy is poured into the sand mold) for 5 min were recorded, with the mean of five records taken as the final results.

FT-IR analysis of the samples was performed by using an IRPrestige-21 infrared spectrometer. For full evaporation of water, all the samples were stored in an oven at $40{ }^{\circ} \mathrm{C}$ for $10 \mathrm{~h}$. After that, the samples were ground into fine powders, and then the powders were mixed with KBr. Finally, the mixture was compressed into thin pills for FT-IR analysis.

The flowability of molding sand was measured by a standard cylinder with a round hole. $185 \mathrm{~g}$ of molding sand was added into the cylinder when the hole was blocked. A cylinder containing sand was placed on the hammering prototype and then hammered ten times while the hole was unblocked. Afterwards, the compacted molding sand was taken out slowly, and the weight of molding sand extruded from the hole was measured as the value of the flowability of molding sand.

The dynamic viscosity of the binder was tested using a NDJ-1 rotary viscometer. The gas evolution of molding sand was tested using an SFZ-type gas evolution instrument. The bonded bridge and fracture morphology of sand core bonded with water glass were observed by a scanning electron microscope (SEM).

\section{Results and discussion}

The strengths of the sand core bonded with unmodified water glass are shown in Table 1. The physical properties of unmodified water glass and molding sand bonded with unmodified water glass are detailed in Table 2 .

Table 1: Tensile strength of sand core bonded with unmodified water glass (MPa)

$\begin{array}{ccc}\sigma_{0} & \sigma_{24} & \sigma_{\mathrm{r}} \\ 1.13 & 1.20 & 0.20\end{array}$

Table 2: Physical properties of unmodified water glass and molding sand bonded with unmodified water glass

\begin{tabular}{|cc|}
\hline Physical properties & Results \\
\hline $\begin{array}{c}\text { Modulus of the unmodified water glass } \\
\text { Dynamic viscosity of the unmodified } \\
\text { water glass }(\mathrm{mPa} \cdot \mathrm{s})\end{array}$ & 2.81 \\
$\begin{array}{c}\text { Flowability of molding sand }(\mathrm{g}) \\
\begin{array}{c}\text { Gas evolution of the sand core } \\
600^{\circ} \mathrm{C} \times 3 \mathrm{~min}\left(\mathrm{ml} \cdot \mathrm{g}^{-1}\right)\end{array}\end{array}$ & 74 \\
\hline
\end{tabular}


Single factor test on the effect of the modification on water glass was conducted. The tensile strengths of the sand core bonded with modified water glass are shown in Table 3.

As indicated by Table 3, the strengths of the sand core are affected by the varying content of modifiers. The satisfactory results are achieved when addition amounts of potassium hydroxide, sodium hexametaphosphate and white sugar are $4 \%, 0.4 \%$, and $0.4 \%$ of water glass in weight, respectively.
In order to make a further improvement to the performance of the sand core, the optimum amount of each modifier was determined by the orthogonal experiment. The orthogonal experiment for the three factors and three levels was designed according to Table 4 . Table 5 shows the $\sigma_{0}, \sigma_{24}$, and $\sigma_{\mathrm{r}}$ of sand core, as well as the range analysis of $\sigma_{\mathrm{r}}$. Figure 1 shows the range analysis of $\sigma_{\mathrm{r}}$ in the orthogonal test.

Table 3: Tensile strength of the sand core bonded with modified water glass (MPa)

\begin{tabular}{|c|c|c|c|c|}
\hline Type of modifier & $\begin{array}{c}\text { Addition amount } \\
\text { (wt. } \% \text { of water glass) }\end{array}$ & $\sigma_{0}$ & $\sigma_{24}$ & $\sigma_{\mathrm{r}}$ \\
\hline \multirow{3}{*}{ Potassium hydroxide } & 2 & 1.85 & 1.90 & 0.09 \\
\hline & 4 & 1.96 & 2.08 & 0.07 \\
\hline & 6 & 1.91 & 1.97 & 0.07 \\
\hline \multirow{3}{*}{ Sodium hexametaphosphate } & 0.2 & 1.25 & 1.26 & 0.03 \\
\hline & 0.4 & 1.32 & 1.35 & 0.02 \\
\hline & 0.6 & 1.30 & 1.30 & 0.02 \\
\hline \multirow{3}{*}{ White sugar } & 0.2 & 1.65 & 1.72 & 0.05 \\
\hline & 0.4 & 1.72 & 1.80 & 0.04 \\
\hline & 0.6 & 1.70 & 1.73 & 0.03 \\
\hline
\end{tabular}

Table 4: Factors and levels of the orthogonal test

\begin{tabular}{cccc} 
& \multicolumn{3}{c}{ Factors } \\
Levels & A (Potassium hydroxide, wt. \%) & B (Sodium hexametaphosphate, wt. \%) & C (White sugar, wt.\%) \\
\hline 1 & 3 & 0.3 & 0.3 \\
2 & 4 & 0.4 & 0.4 \\
3 & 5 & 0.5 & 0.5
\end{tabular}

Table 5: Results and analysis of the orthogonal experiment and range analysis of $\sigma_{\mathrm{r}}$

\begin{tabular}{ccccccc}
$\begin{array}{c}\text { Test } \\
\text { number }\end{array}$ & $\begin{array}{c}\text { A (Potassium } \\
\text { hydroxide, wt. \%) }\end{array}$ & $\begin{array}{c}\text { B (Sodium } \\
\text { hexametaphosphate, wt. \%) }\end{array}$ & $\begin{array}{c}\text { C } \\
\text { (White sugar, wt. \%) }\end{array}$ & $\sigma_{0}(\mathrm{MPa})$ & $\sigma_{24}(\mathrm{MPa})$ & $\boldsymbol{\sigma}_{\mathrm{r}}(\mathrm{MPa})$ \\
\hline 1 & $\mathrm{~A} 1$ & $\mathrm{~B} 1$ & $\mathrm{C} 1$ & 2.37 & 2.40 & 0.05 \\
2 & $\mathrm{~A} 1$ & $\mathrm{~B} 2$ & $\mathrm{C} 2$ & 2.57 & 2.59 & 0.04 \\
3 & $\mathrm{~A} 1$ & $\mathrm{~B} 3$ & $\mathrm{C} 3$ & 2.39 & 2.41 & 0.03 \\
4 & $\mathrm{~A} 2$ & $\mathrm{~B} 1$ & $\mathrm{C} 2$ & 2.44 & 2.46 & 0.04 \\
5 & $\mathrm{~A} 2$ & $\mathrm{~B} 2$ & $\mathrm{C} 3$ & 2.40 & 2.42 & 0.01 \\
6 & $\mathrm{~A} 2$ & $\mathrm{~B} 3$ & $\mathrm{C} 1$ & 2.43 & 2.45 & 0.02 \\
7 & $\mathrm{~A} 3$ & $\mathrm{~B} 1$ & $\mathrm{C} 3$ & 2.47 & 2.48 & 0.04 \\
8 & $\mathrm{~A} 3$ & $\mathrm{~B} 2$ & $\mathrm{C} 1$ & 2.39 & 2.42 & 0.03 \\
9 & $\mathrm{~A} 3$ & $\mathrm{~B} 3$ & $\mathrm{C} 2$ & 2.36 & 2.39 & 0.01 \\
$\mathrm{k} 1$ & 0.040 & 0.043 & 0.033 & & & \\
k2 & 0.023 & 0.027 & 0.030 & & &
\end{tabular}




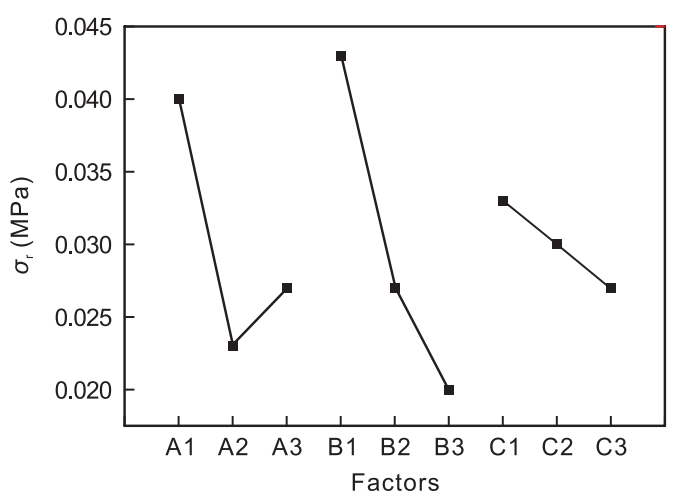

Fig. 1: Range analysis of $\sigma_{\mathrm{r}}$ in orthogonal experiment

As indicated in Table 5 and Fig. 1, a different proportion of modifiers has no significant effect on $\sigma_{24}$ and $\sigma_{0}$, but has a considerable impact on $\sigma_{\mathrm{r}}$ of the sand core. From Fig. 1, it can be seen that the influence degree of each factor on $\sigma_{\mathrm{r}}$ is $\mathrm{B}>\mathrm{A}>\mathrm{C}$, and that the optimal combination of the factors is $\mathrm{A}_{2} \mathrm{~B}_{3} \mathrm{C}_{3}$, in which the addition of potassium hydroxide, sodium hexametaphosphate and white sugar is $4 \%, 0.5 \%$ and $0.5 \%$ of water glass in weight, respectively. A verification test was performed according to the optimal combination of $\mathrm{A}_{2} \mathrm{~B}_{3} \mathrm{C}_{3}$, with the result shown in Table 6.

Table 6: Results of verification test (MPa)

$\begin{array}{ccc}\sigma_{0} & \sigma_{24} & \sigma_{\mathrm{r}} \\ 2.46 & 2.49 & 0.01\end{array}$
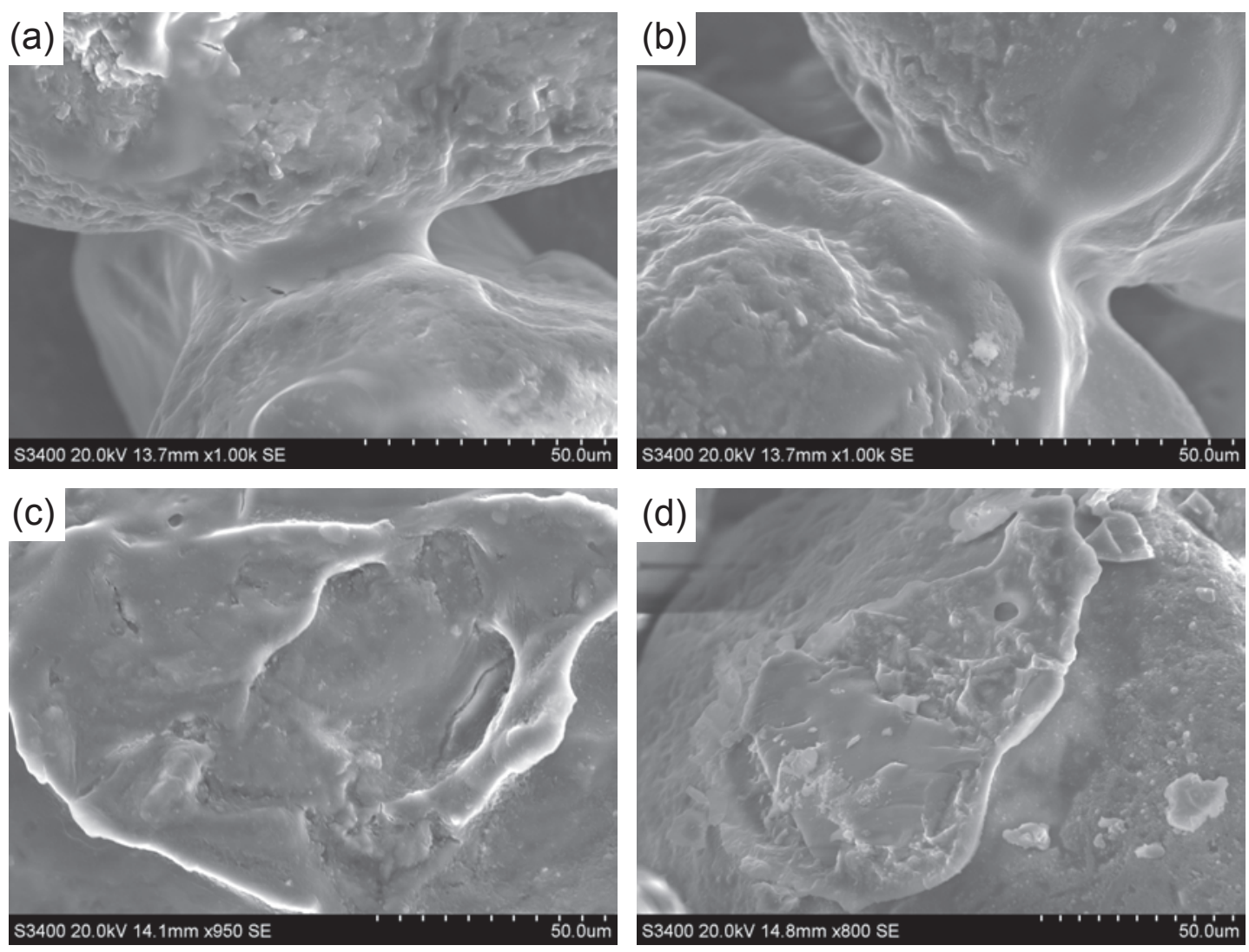

Fig. 2: Characteristics of bonded bridge ( $a$ and b) and fracture morphology (c and d): (a) and (c) bonded with unmodified water glass; (b) and (d) bonded with modified water glass 
on the fracture surface of the bonded bridge with unmodified water glass, while the fracture surface of the bonded bridge with modified water glass is relatively complete, which suggests that the bonded bridge with modified binder possessed a high strength.

Table 7 shows the physical properties of modified water glass with the combination of $\mathrm{A}_{2} \mathrm{~B}_{3} \mathrm{C}_{3}$ and the molding sand bonded with this modified water glass.

Table 7: Physical properties of the modified water glass and molding sand bonded with this modified water glass

\begin{tabular}{|cc|}
\hline Physical properties & Results \\
\hline $\begin{array}{c}\text { Modulus of modified water glass } \\
\text { Dynamic viscosity of the modified } \\
\text { water glass }(\mathrm{mPa} \cdot \mathrm{s})\end{array}$ & 2.64 \\
$\begin{array}{c}\text { Flowability of molding sand }(\mathrm{g}) \\
\quad \text { Gas evolution of sand core } \\
600^{\circ} \mathrm{C} \times 3 \mathrm{~min}\left(\mathrm{ml}^{-1} \mathrm{~g}^{-1}\right)\end{array}$ & 80 \\
\end{tabular}

Comparing Table 7 with Table 2, it can be seen that the modulus of modified water glass is reduced from 2.81 to 2.64 , which results from the addition of potassium hydroxide. The dynamic viscosity of the binder improves from $74 \mathrm{mPa} \cdot \mathrm{s}$ to $80 \mathrm{mPa} \cdot \mathrm{s}$ after the addition of modifiers. Meanwhile, the modified water glass binder is still uniformly distributed on the surface of the molding sand, as shown in Fig. 2(b). The flowability of molding sand bonded with modified water glass is enhanced from $2.15 \mathrm{~g}$ to $2.21 \mathrm{~g}$, which is favorable for making the molding sand more compact. The improvement of the compactness of molding sand is favorable for improving the quality of the bonded bridge, thus, compared with unmodified water glass, the $\sigma_{0}$ and $\sigma_{24}$ of the sand core with modified water glass were increased from 1.13 $\mathrm{MPa}$ and $1.20 \mathrm{MPa}$ to $2.46 \mathrm{MPa}$ and $2.49 \mathrm{MPa}$, respectively. The - $\mathrm{OH}$ concentrations of water glass are increased by the addition of potassium hydroxide, and a high modulus water glass was obtained from the reaction between -OH groups and $\mathrm{SiO}_{2}$ particles widely distributed in the water glass ${ }^{[14-16]}$. According to the state of the $\mathrm{Na}_{2} \mathrm{O}-\mathrm{SiO}_{2}-\mathrm{H}_{2} \mathrm{O}$ system ${ }^{[17]}$, the bonded bridge between water glass and sand particle is easily formed with the increase of modulus ${ }^{[18,19]}$. Thus, a kind of high strength bonded bridge develops between the sand particles. As a result, the $\sigma_{0}$ and $\sigma_{24}$ of the sand core are improved by modified water glass.

Among the three additives, the white sugar decomposes at high temperature to release gas, thus causing the gas evolution of molding sand bonded with modified water glass to increase from $4.9 \mathrm{ml} \cdot \mathrm{g}^{-1}$ to $5.3 \mathrm{ml} \cdot \mathrm{g}^{-1}$.

The FT-IR analysis result of the unmodified and modified water glass is shown in Fig. 3. According to the infrared analysis manual ${ }^{[20,21]}$, there are new groups appearing in the modified water glass, among which, $1,475 \mathrm{~cm}^{-1}, 1,019 \mathrm{~cm}^{-1}, 783 \mathrm{~cm}^{-1}$ and $622 \mathrm{~cm}^{-1}$ are related to $\mathrm{PO}_{3}^{-}, \mathrm{PO}_{4}{ }^{3-}, \mathrm{C}-\mathrm{O}-\mathrm{C}$ and Si-O-C, respectively.

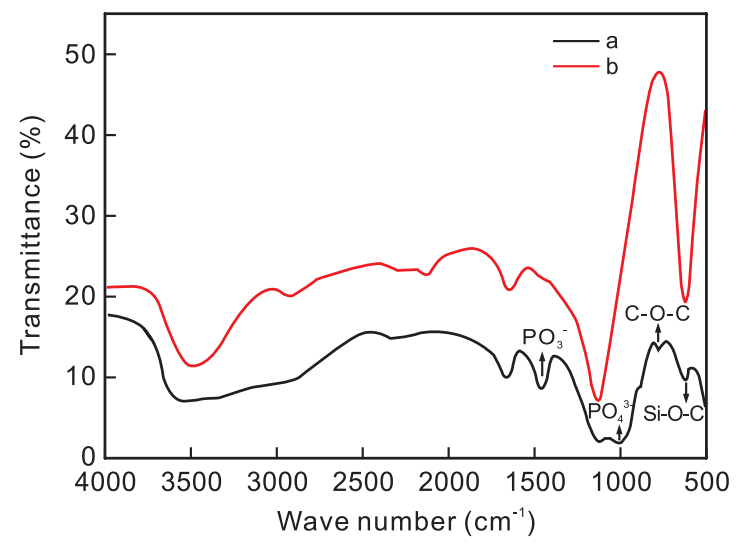

Fig. 3: FT-IR analysis results of the sand core: (a) FT-IR line of the modified water glass; (b) FT-IR line of the unmodified water glass

As a sort of polyphosphate, sodium hexametaphosphate contains dozens of $\mathrm{PO}_{3}{ }^{-}$groups in general. When the $-\mathrm{OH}$ concentration is high, part of the $\mathrm{PO}_{3}^{-}$groups can be hydrolyzed to $\mathrm{PO}_{4}{ }^{3-}$ groups. The structure of $\mathrm{PO}_{4}{ }^{3-}$ is tetrahedron which is the same as the $\mathrm{SiO}_{4}{ }^{4-}$ in the water glass binder. After hardening, a composite unified network with the phosphorusoxygen tetrahedron $\left(\mathrm{PO}_{4}{ }^{3-}\right)$ and the silicon-oxygen tetrahedron $\left(\mathrm{SiO}_{4}{ }^{4-}\right)$ was constructed, and the bonded strength of binder was improved to some extent. During the cooling process from high temperature, the decomposition of the bonded bridge was promoted by stress, which results from the different expansion coefficients between phosphorus-oxygen tetrahedron $\left(\mathrm{PO}_{4}{ }^{3-}\right)$ and the silicon-oxygen tetrahedron $\left(\mathrm{SiO}_{4}{ }^{4-}\right)$, thus the collapsibility of the sand core was improved. The $\sigma_{\mathrm{r}}$ of sand core is decreased with the addition of white sugar, which is decomposed at high temperature to accelerate the fracture of the bonded bridge. Consequently, the collapsibility of the sand core was improved by the addition of white sugar.

\section{Conclusions}

The tensile strength and collapsibility of the sand core were improved through the modification of water glass, and the mechanism of collapsibility improvement of the sand core was revealed by the FT-IR analysis. Accordingly, the following conclusions can be drawn:

(1) The different modified water glass binders are obtained through the addition of modifiers in different amounts. As determined by the combination of single factor test and orthogonal test, the optimal proportion of water glass, potassium hydroxide, sodium hexametaphosphate and white sugar as addition is 1000: 40: 5: 5 in weight.

(2) For the sand core bonded by a warm core box process with $2 \%$ (wt.) modified water glass with the optimal proportion and $0.6 \%$ (wt.) micro silicon powders, the tensile strength at room temperature $\left(\sigma_{0}\right)$ and at $25^{\circ} \mathrm{C}$ and $40 \% \mathrm{RH}$ for $24 \mathrm{~h}\left(\sigma_{24}\right)$ is $2.46 \mathrm{MPa}, 2.49 \mathrm{MPa}$, respectively. Meanwhile, the high temperature residual tensile strength $\left(\sigma_{\mathrm{r}}\right)$ of sand core under $600{ }^{\circ} \mathrm{C}$ for $5 \mathrm{~min}$ is $0.01 \mathrm{MPa}$. 
(3) The dynamic viscosity of modified water glass and flowability of molding sand bonded with modified water glass are both improved. In the meantime, the bonded strengths of sand core are increased as a result of the reaction between $-\mathrm{OH}$ groups from addition of potassium hydroxide and $\mathrm{SiO}_{2}$ particles widely distributed in the sand core.

(4) The bonded bridges of the sand core using modified water glass are easily broken during the cooling process, promoted by different expansion coefficients between phosphorus-oxygen tetrahedron $\left(\mathrm{PO}_{4}^{3-}\right)$ and silicon-oxygen tetrahedron $\left(\mathrm{SiO}_{4}{ }^{4-}\right)$, along with the decomposition of white sugar at high temperatures. Thus, the collapsibility of the sand core using modified water glass is significantly improved.

\section{References}

[1] Fan Z T, Long W, Liu F C. Environmental characteristics of mold casting and development trend of binder. Journal of Hubei University of Technology, 2014, 29(5): 1-5. (In Chinese)

[2] Song L, Liu W H, Li Y M, et al. Humidity-resistant inorganic binder for sand core-making in foundry practice. China Foundry, 2018, 16(4): 267-271.

[3] Ünlü N, Odabas A. Development and evaluation of a new ecofriendly sodium silicate-based binder system. International Journal of Metalcasting, 2018, 12: 765-771.

[4] Fox J T, Cannon F S, Brown N R, et al. Comparison of a new green foundry binder with conventional foundry binders. International Journal of Adhesion \& Adhesives, 2012, 34: $38-45$

[5] Wang J, Yang J H, Zhao L. Study on recycling technology of sodium silicate based on green casting. Foundry Technology, 2018, 39(3): 533-536. (In Chinese)

[6] Zaretskiy L. Hydrous solid silicates in new foundry binders. International Journal of Metalcasting, 2018, 12(2): 275-291.

[7] Izdebska-Szanda I, Baliński A. New generation of ecological silicate binder. Engineering Procedia, 2011, 10: 887-893.

[8] Zaretskiy L. Microsilica in sodium silicate bonded sands. International Journal of Metalcasting, 2019, 13(1): 58-72.
[9] Nilsen E, Einarsrud M A, Puputti J, et al. Preparation and characterization of binder for inorganic composites made from amorphous mineral raw material. Journal of Sol-Gel Science and Technology, 2005, 35(2): 143-150.

[10] Sun Y Q, Pan J Q, Chen L Z, et al. Effect of surface active agent on properties of sodium silicate sand. Journal of Technology, 2017, 17(1): 45-48. (In Chinese)

[11] Yang C. Effect of ultra-fine powder modifying sodium silicate on foundry sand. Hot Working Technology, 2014, 43(19): 8284. (In Chinese)

[12] Zhu Y, Yu Y G, Zhou L S. Study on poly (ethylene oxide) modified sodium silicate binder. Foundry, 2006, 8(55): 839841. (In Chinese)

[13] Zaretskiy L. Modified silicate binder's new developments and applications. International Journal of Metalcasting, 2015, 10(1): 88-99.

[14] Kouassi S S, Tognonvi M T, Soro J, et al. Consolidation mechanism of materials obtained from sodium silicate solution and silica-based aggregates. Journal of Non-Crystalline Solids, 2011, 357(15): 3013-3021.

[15] Tognonvi M T, Rossignol S, Bonnet J P. Effect of alkali cation on irreversible gel formation in basic medium. Journal of NonCrystalline Solids, 2011, 357(1): 43-49.

[16] Luukkonen T, Sreenivasan H, Abdollahnejad Z, et al. Influence of sodium silicate powder silica modulus for mechanical and chemical properties of dry-mix alkali-activated slag mortar. Construction and Building Materials, 2020, 233: 117354.

[17] Zhu C X, Lu C, Ji D S. Basic theory of water glass sand. Shang Hai: Shanghai Jiaotong University Press, 2000: 67-68.

[18] Tognonvi M T, Soro J, Rossignol S. Physical-chemistry of silica/ alkaline silicate interactions during consolidation. Part 1: Effect of cation size. Journal of Non-Crystalline Solids, 2012, 358(1): 81-87.

[19] Tognonvi M T, Soro J, Gelet J L, et al. Physico-chemistry of silica/Na silicate interactions during consolidation. Part 2: Effect of $\mathrm{pH}$. Journal of Non-Crystalline Solids, 2012, 358(3): 492-501.

[20] Weng S F, Xu Y Z. Fourier transform infrared spectrum analysis. Shang Hai: Shanghai Jiaotong University Press, 2016: 326-416.

[21] Xu J. Infrared spectroscopy analysis of modified sodium silicate. Foundry, 2008, 57(8): 834-837. (In Chinese) 